\title{
MANAGEMENT OF CLUBFOOT BY PONSETI METHOD
}

\author{
Polisetty Venkata Shyam Prasad ${ }^{1}$, Lakshmi Sumana Voruganti ${ }^{2}$
}

${ }_{1}^{1}$ Associate Professor, Department of Orthopaedics, Andhra Medical College, Visakhapatnam, Andhra Pradesh. ¿Senior Resident, Department of Orthopaedics, Andhra Medical College, Visakhapatnam, Andhra Pradesh.

\section{ABSTRACT}

\section{BACKGROUND}

Talipes equinovarus is a congenital deformity consisting of ankle equinus, hindfoot varus, forefoot adduction and cavus of fo ot. Currently, close management such as serial casting is known as the gold standard treatment of idiopathic clubfoot. Long-term studies have reported excellent results in using the Ponseti method of clubfoot manipulation and serial casting accompanied with Achilles tendon tenotomy and foot abduction brace. Ponseti method has showed better range of motion and push-off strength compared to surgical release.

Aims and Objectives- To study the clinical profile of clubfoot- sex ratio, laterality and severity. To assess the average duration of the treatment by Ponseti method in comparison to literature, to study the results of the treatment by Ponseti. To study the relation between initial Pirani scores and outcome.

\section{MATERIALS AND METHODS}

In the present case series, 20 cases of idiopathic clubfoot were treated by Ponseti method and assessed by Pirani scoring system. Using a prescribed format, the data was collected, assessed, analysed and compared with other series and observations were made.

\section{RESULTS}

The demographic profile of male: female sex ratio of 2.3: 1 was seen. Bilaterality in $45 \%$ of cases was seen with right-sided slightly more common. Group 2 cases were more common than Group 1 and 3. 80\% of cases required tenotomy.

\section{CONCLUSION}

Ponseti's method of conservative management is very effective in treating idiopathic clubfoot. Patients with low Pirani score respond faster to treatment. Tenotomy is necessary to correct equinus deformity. Maintenance of corrected deformity in a brace is necessary to avoid recurrence.

\section{KEYWORDS}

Ponseti Technique, Clubfoot, Pirani Score, Percutaneous Tenotomy.

HOW TO CITE THIS ARTICLE: Prasad PVS, Voruganti LS. Management of clubfoot by Ponseti method. J. Evolution Med. Dent. Sci. 2018;7(12):1484-1487, DOI: 10.14260/jemds/2018/336

\section{BACKGROUND}

Talipes equinovarus is a congenital deformity consisting of ankle equinus, hindfoot varus, forefoot adduction and clubfoot is probably the most common congenital orthopaedic condition requiring intensive treatment. It most likely represents congenital dysplasia of all musculoskeletal tissues distal to the knee. Incidence is 1 in thousand live births. ${ }^{1}$ Three times more common in male children. If one child in a family has the deformity, the chance of $2^{\text {nd }}$ child having the deformity is 1 in $35.32 .5 \%$ of monozygotic twins have clubfoot. $2.9 \%$ of dizygotic twins have clubfoot.

Currently, closed management such as serial casting is known as the gold standard treatment of idiopathic clubfoot. Long-term studies have reported excellent results in using the Ponseti method of clubfoot manipulation and serial casting accompanied with Achilles tendon tenotomy and foot abduction brace. Ponseti method has showed better range of motion and push-off strength compared to surgical release.

'Financial or Other Competing Interest': None.

Submission 09-02-2018, Peer Review 04-03-2018,

Acceptance 10-03-2018, Published 19-03-2018.

Corresponding Author:

Lakshmi Sumana Voruganti,

Department of Orthopaedics King George Hospital,

Maharani Peta, Visakhapatnam.

E-mail:drsumanavl@gmail.com

DOI: $10.14260 /$ jemds $/ 2018 / 336$
The purpose of our study is to study outcome of Ponseti technique in idiopathic club foot, to study the clinical profile of clubfoot- sex ratio, laterality and severity to assess the average duration of the treatment by Ponseti method in comparison to literature and to study the relation between initial Pirani scores and outcome.

\section{MATERIALS AND METHODS}

The case series was studied at King George Hospital, Visakhapatnam, after approval from Institutional Ethical Committee between Jan. 2015 to Sept. 2016. Twenty patients were treated, and results were assessed after a follow-up of one year. Inclusion criteria: Idiopathic clubfoot upto 1 year of age. Neurogenic clubfoot and Syndromic clubfoot and cases previously operated were excluded from the study.

All patients were treated on an OPD basis. Detailed history to find out the cause of clubfoot was taken including family history of clubfoot and complication like teratogenic drug intake and radiation exposure. Detailed examination to exclude other anomalies and spinal abnormalities was done.

After the Diagnosis of Idiopathic Clubfoot was made, the Foot was assessed for Severity by Pirani Scoring ${ }^{2}$

A. Mid foot score (MS) upto $3(0=$ normal, $3=$ severe $)$.

B. Hind foot score (HS) of upto $3(0=$ normal, $3=$ severe $)$.

C. Total score (TS) of upto $6(0=$ normal, $6=$ severe $)$.

Scoring was done each week for MS, HS and TS. 
Tenotomy is indicated when HS $>1$ MS $<1$ and head of talus is covered.

\section{Categorisation of Feet:}

1. Group 1: Pirani score of $1.5-2.5$.

2. Group 2: Pirani score of $3-4.5$.

3. Group 3: Pirani score $>5$.

\begin{tabular}{|lccc|}
\hline Deformity & $\begin{array}{c}\text { Present and } \\
\text { fixed (1) }\end{array}$ & Mild (0.5) & Absent (0) \\
\hline Hind-foot deformities & 1 & 0.5 & 0 \\
$\begin{array}{l}\text { Posterior heel crease } \\
\text { Empty heel }\end{array}$ & 1 & 0.5 & 0 \\
$\begin{array}{l}\text { Rigidity of equinus } \\
\text { Mid-foot deformities }\end{array}$ & 1 & 0.5 & 0 \\
$\quad \begin{array}{l}\text { Gurvature of lateral border } \\
\text { of foot }\end{array}$ & 1 & 0.5 & 0 \\
Medial crease & 1 & 0.5 & 0 \\
Lateral head of talus & 1 & 0.5 & 0 \\
Total score & & & \\
\hline
\end{tabular}

Table 1. Pirani Score

After the Treatment the Results were Graded as Good, Fair, Poor-

Good: Foot with Pirani score of 1 or less is considered good.

Fair: If additional surgical procedure like subtalar release or posterior ankle release were done to get correction.

Poor: Ponseti technique failed to obtain complete correction of foot.

\section{MANIPULATION METHOD $3,4,5$}

Manipulation and casting was done as Ponseti's method. The foot was held with one hand at the neck of the talus and the other hand was used to correct the deformity. Right hand was used to correct the deformity of right foot and left for left, Only cavus, adduction and inversion of hind foot were corrected together at the first and the subsequent visits. Equinus was corrected only after the other deformities were corrected. If other deformities were not corrected, it was considered resistant. Foot was held by one hand curling behind the back of the heel and the thumb pressing on the neck of the talus. With the other hand, the forefoot was held at the neck of the 1st metatarsal and forefoot was supinated thereby correcting the cavus. Then the foot is abducted to 70 degrees to correct first the forefoot abduction and then by the transmitted force to the calcaneum the hindfoot inversion. The foot was immobilised in 70-degree abduction without correcting equinus in above knee cast upto groin with knee in flexion.

\section{Follow-Up}

The patients were followed up every week for remanipulation and change of cast correcting the three deformities and clinically assessing the improvement by Pirani score.

Percutaneous tenotomy of Achilles tendon was done under local anaesthesia and above knee cast upto groin was applied with knee in flexion. Complete tenotomy above the insertion of Achilles tendon was done with foot held in dorsiflexion to avoid the neurovascular structures posteromedially. The foot was splinted in Foot Abduction Bar
(FAB) for 23 hours for 3 months, after which it was advised to be worn at night times for 7 years. In FAB the foot is splinted in 70 degrees of external rotation in bilateral cases and the affected foot in 70 degrees and normal foot in 30 degrees of external rotation in unilateral cases, in either case both feet are kept in 20 degrees of dorsiflexion.

Patients were followed up monthly for 1 year and the results were evaluated at the end of 1 year.

\section{CASE}

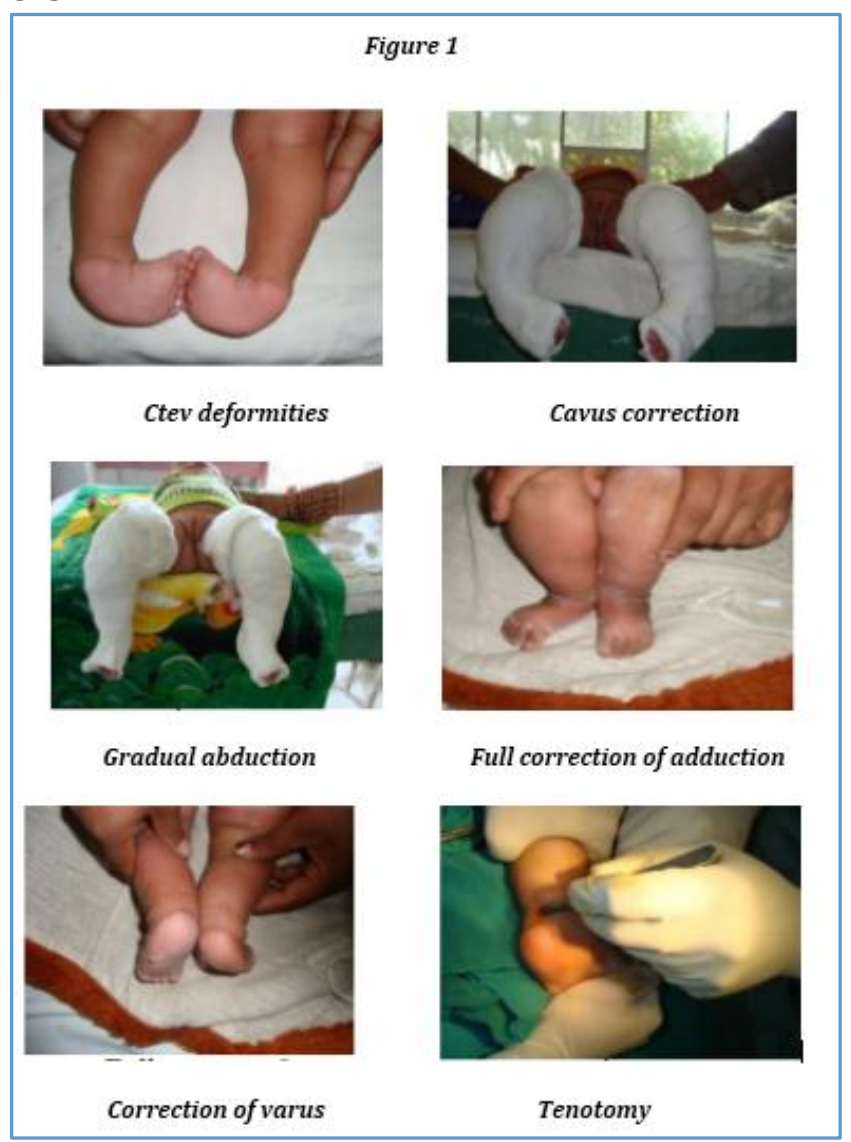

RESULTS

\begin{tabular}{|c|c|}
\hline Total No. of Pts. & $\mathbf{2 0}$ \\
\hline Male & 14 \\
\hline Female & 6 \\
\hline \multicolumn{2}{|c|}{ Table 2. Sex Ratio of the Patient } \\
\hline
\end{tabular}

In our study of 20 patients, male: female ratio of 2.3: 1 was observed.

\begin{tabular}{|c|c|}
\hline Total No. of Pts. & $\mathbf{2 0}$ \\
\hline Bilateral & 9 \\
\hline Right & 6 \\
\hline Left & 5 \\
\hline \multicolumn{2}{|c|}{ Table 3. Laterality } \\
\hline
\end{tabular}

$45 \%$ bilaterality was observed with right side slightly more common.

\begin{tabular}{|c|c|}
\hline Group & No. of Cases \\
\hline Group 1 & 5 \\
\hline Group 2 & 11 \\
\hline Group 3 & 4 \\
\hline \multicolumn{2}{|c|}{ Table 4. Distribution of Severity } \\
\hline
\end{tabular}

Group 2 cases are more than Group 1 and 3. 


\begin{tabular}{|c|c|c|c|c|}
\hline Grade & $\begin{array}{c}\text { No. of } \\
\text { Cases }\end{array}$ & Good & Fair & Poor \\
\hline Group 1 & 5 & $5(100 \%)$ & & \\
\hline Group 2 & 11 & $7(63.63 \%)$ & $3(27.27 \%)$ & $1(9.09 \%)$ \\
\hline Group 3 & 4 & $1(25 \%)$ & $2(50 \%)$ & $1(25 \%)$ \\
\hline \multicolumn{5}{|c|}{ Table 5. Results depending on Grade } \\
\hline
\end{tabular}

Results were more satisfactory in cases with low Pirani score.

\begin{tabular}{|c|c|}
\hline Group & Average No. of Casts \\
\hline Group 1 & 6 \\
\hline Group 2 & 8 \\
\hline Group 3 & 12 \\
\hline Table 6. Initial Pirani Score vs. Number of Casts \\
\hline
\end{tabular}

Number of casts required to achieve complete correction increased with increase in the initial Pirani score.

\begin{tabular}{|c|c|}
\hline Total Patients & $\mathbf{2 0}$ \\
\hline Tenotomy & 16 \\
\hline Non-Tenotomy & 4 \\
\hline \multicolumn{2}{|c|}{ Table 7. Cases requiring Tenotomy } \\
\hline
\end{tabular}

$16(80 \%)$ of 20 club feet needed tenotomy.

\begin{tabular}{|c|c|}
\hline Compliance & No. of Cases \\
\hline Yes & 14 \\
\hline No & 6 \\
\hline \multicolumn{2}{|c|}{ Table 8. Compliance with Braces } \\
\hline
\end{tabular}

$70 \%$ of cases showed compliance with braces.

Average 8 casts were needed by the patients with an average of 2.5 months of treatment.

\begin{tabular}{|c|c|}
\hline Education of Parents & Compliance \\
\hline Educated & 14 \\
\hline Not Educated & 6 \\
\hline
\end{tabular}

Table 9. Education of Parents vs. Compliance of Treatment

Compliance is better when parents are educated.

\begin{tabular}{|c|c|}
\hline Complication & No. of Patients \\
\hline Abrasions & 3 \\
\hline Blisters & 2 \\
\hline \multicolumn{2}{|c|}{ Table 10. Complications } \\
\hline
\end{tabular}

\section{DISCUSSION}

Congenital idiopathic clubfoot is a common congenital foot deformity, is treated by widely accepted and acclaimed Ponseti technique to achieve early correction.

In the present study, 20 cases of idiopathic clubfoot were treated by Ponseti method to assess the role of Pirani scoring system. Using a prescribed format, the data was collected, assessed, analysed and compared with other series and observations were made as follows.

\begin{tabular}{|c|c|c|c|}
\hline Studies & $\begin{array}{c}\text { No. of } \\
\text { Patients }\end{array}$ & $\begin{array}{c}\text { Males } \\
(\%)\end{array}$ & $\begin{array}{c}\text { Females } \\
(\%)\end{array}$ \\
\hline Kite et al $^{6}$ & 1509 & 70 & 30 \\
\hline Turco $^{7}$ & 468 & 71.4 & 28.6 \\
\hline $\begin{array}{c}\text { Changulani et } \\
\text { al }^{8}\end{array}$ & 66 & 75.7 & 24.3 \\
\hline Raju Rijal et al $^{9}$ & - & 76.2 & 33.8 \\
\hline Present Study & 20 & 70 & 30 \\
\hline \multicolumn{4}{|c|}{ Table 11. Sex Ratio } \\
\hline
\end{tabular}

In the present study, males were (14 cases, $70 \%)$ more commonly involved in accordance to other studies.

\section{Side Affected}

\begin{tabular}{|c|c|c|}
\hline Studies & Bilateral (\%) & Unilateral (\%) \\
\hline Wyne Davis $^{10}$ & 44 & 56 \\
\hline Turco $^{7}$ & 56.7 & 43.3 \\
\hline Ponseti $^{11}$ & 40 & 60 \\
\hline Changulani et al $^{8}$ & 52 & 48 \\
\hline Present Study & 45 & 55 \\
\hline \multicolumn{2}{|c|}{ Table 12. Side Effected } \\
\hline
\end{tabular}

As regards to laterality, in our study $45 \%$ (9 cases) were bilateral and 11 cases (55\%) (6 right and 5 left) were unilateral in concordance with other series.

\section{Tenotomy}

In the present study, 16 feet (80\%) underwent tenotomy comparable to studies done by Scher et al and Colburn et al. ${ }^{12}$ In M Changulani et al study, $85 \%(n=100)$ patients required tendoachilles tenotomy. ${ }^{8}$ In Noam Bor et al study, 97\% $(\mathrm{n}=36 \%)$ patients required tendoachilles tenotomy. ${ }^{13}$ Colburn et al and Scher et al ${ }^{12}$ required percutaneous tendoachilles tenotomy in $67 \%$ and $72 \%$ feet respectively.

\section{Initial Pirani Score vs. Number of Casts}

In our study, the number of casts required to achieve complete correction increased with increase in the initial Pirani score. Raju Rijal ${ }^{9}$ et al showed in their series, faster rates of decrease in Pirani score treated by Ponseti technique and less number of casts with less Pirani score. PJ Dyer and N Davis ${ }^{14}$ in their series showed at least 4 casts required for full correction of initial Pirani score of 4 similar to our study. Noam Bor et al in their series had mean total Pirani score of 4.7 ( 2 to 6 ) and mean number of casts required was 6 similar to our study. ${ }^{15}$

\section{Number of Casts}

In our study, the mean number of casts required to correct the deformity was 8 (range $4-15$ ) and was comparable to other studies.

In PJ Dyer et al study, the mean number of casts required to correct the deformity was 5.31.14 Lehman et al15 was able to obtain correction with casting average of 5.4 (range 4 - 9).

In our study Group 2 cases are more than Group 1 and 3.

Results were more satisfactory in cases with low pirani score. Education of the parents plays an important role in the compliance of the cases.

In the present study only two complications were observed, abrasion and blister. Lehman et al reported 25 complications with rate of $10.2 \%$. Cast saw injuries were commonest accounting for $25 \%$ of complications. 4 In our study, no complication of cast saw injury as pop was removed by soaking method. Dobbs et al $^{16}$ retrospectively reviewed 134 consecutive infants with 219 clubfeet and detected that 4 patients had serious bleeding complication following percutaneous tendoachilles tenotomy. However, no such serious bleeding was recorded in the present study. 


\section{CONCLUSION}

Ponseti's method of conservative management is very effective in treating idiopathic clubfoot. Patients with low Pirani score respond faster to treatment. Tenotomy is necessary to correct equinus deformity. Maintenance of corrected deformity in a brace is necessary to avoid recurrence.

We have observed that duration for correction of different deformities by Ponseti is not uniform. It varied in each patient depending on initial Pirani score, which indicated the initial elasticity of the musculoligamentous structures. Children of educated parents had shown better results, as they could understand the pathomechanics and importance of plaster care. Good casting technique is necessary to avoid complications.

Limitation of our study is a short follow-up.

\section{REFERENCES}

[1] Ponseti IV. Current concepts review: treatment of congenital clubfoot. J Bone Joint Surg Am 1992;74(3):448-54.

[2] Pirani S, Outerbridge H, Moran M, et al. A method of evaluating the virgin clubfoot with substantial interobserve reliability. Presented at the annual meeting of Pediatric Orthopaedic Society of North America, Miami, Florida: 1995.

[3] Ponseti IV, Smoley EN. Congenital clubfoot: the results of treatment. J Bone Joint Surg Am 1963;45A:261-75.

[4] Ponseti IV. Congenital clubfoot: fundamentals of treatment. Oxford, UK: Oxford University Press 1996.

[5] Ponseti I, Morcuende JA, Mosca V, et al. Clubfoot: Ponseti management. $2^{\text {nd }}$ edn. Global-Help Publication 2005.
[6] Kite JH. Principles involved in the treatment of congenital clubfoot. J Bone Joint Surg 1939;21:595606.

[7] Turco VJ. Clubfoot. Churchill Livingstone 1981:1-84.

[8] Changulani M, Garg NK, Rajagopal TS. Treatment of idiopathic clubfoot using the Ponseti method. Initial experience. J Bone Joint Surg (Br) 2006;88(10):13857.

[9] Rijal R, Shrestha BP, Singh GK, et al. Comparision of Ponseti and Kite's method of treatment for idiopathic clubfoot. Indian J Orthop 2010;44(2):202-7.

[10] Wynne-Davies R. Talipes equinovarus. A review of eighty four cases after completion of the treatment. J Bone Joint Surg 1964;46:464-76.

[11] Laaveg SJ, Ponseti IV. Long-term results of treatment of congenital clubfoot. J Bone Joint Surg Am 1980;62(1):23-31.

[12] Colburn M, Williams M. Evaluation of the treatment of idiopathic clubfoot by using the Ponseti method. J Foot Ankle Surg 2003;42(5):259-67.

[13] Bor N, Herzenberg JE. Ponseti clubfoot treatment in older children for whom traditional casting has failed. Paper no. 053 AAOS-Podium presentations, Dallas, TX Feb: 2002.

[14] Dyer PJ, Davis N. The role of the Pirani scoring system in the management of clubfoot by the Ponseti method. J Bone Joint Surg (Br) 2006;88(8):1082-4.

[15] Lehman WB, Mohaideen A, Madan S, et al. A method for the early evaluation of the Ponseti (Iowa) technique for the treatment of idiopathic clubfoot. J Pediatr Orthop B 2003;12(2):133-40.

[16] Dobbs MB, Morcuende JA, Gurnett CA, et al. Treatment of idiopathic clubfoot: an historical review. Iowa Orthop J 2000;20:59-64. 